\title{
Liver Angiosarcoma
}

National Cancer Institute

\section{Source}

National Cancer Institute. Liver Angiosarcoma. NCI Thesaurus. Code C4438.

A malignant vascular neoplasm arising from the liver. 